\title{
La "verdad verdadera" del duelo. Entrevista a la artista Erika Diettes
}

\section{María Mercedes Andrade / Universidad de los Andes}

Erika Diettes (Colombia, 1978) es artista visual y comunicadora social de la Pontificia Universidad Javeriana. Tiene además una maestría en Antropología de la Universidad de los Andes. Su obra Silencios (2005) explora los retratos de los testimonios de sobrevivientes judíos de la Shoá que se refugiaron en Colombia. Su obra posterior se centra en el conflicto armado colombiano. Entre estas está Río abajo (2008), donde Diettes recoge y fotografía objetos, en su mayoría prendas de vestir, que los familiares de personas asesinadas o desaparecidas aportaron para la creación de la obra. A su vez, Sudarios (2011) está conformada por fotografías de mujeres víctimas del conflicto, impresas sobre telas de gran formato y expuestas en lugares sagrados. En la instalación Relicarios (2011-2016) los objetos de las familias de personas desaparecidas o asesinadas son expuestos dentro de relicarios hechos de polímero de caucho.

Diettes ha expuesto en el Museo de Bellas Artes de Houston, el Centro Cultural Recoleta (Buenos Aires), el ExTeresa Arte Actual (Ciudad de México), y en distintas instituciones en Estados Unidos, España, Australia, Polonia, República Dominicana, Ecuador y Chile. En Colombia ha presentado su trabajo en el Museo de Antioquia, el Museo de Arte Moderno de Bogotá, el Museo Nacional de Colombia y el Museo de la Universidad Nacional de Colombia, además de las iglesias en las que sus obras Río abajo o Sudarios han sido exhibidas. La artista fue finalista en los Visionary Awards de 2015. Recientemente, Diettes obtuvo la beca de creación otorgada por Tim Hetherington y el World Press Photo Foundation Fellowship (2017-2018).

La siguiente entrevista se llevó a cabo el 12 de septiembre de 2019 en el estudio de la artista, en el barrio Las Nieves de Bogotá.

MMA: Podría decirse que diferentes actores han participado en la lucha por la representación del conflicto colombiano: desde actores institucionales (Jurisdicción Especial de Paz, Comisión de la Verdad, Centro de Memoria Histórica, etc.), pasando por la representación por parte de las mismas víctimas (en los documentos y libros, por ejemplo, que ha publicado el Centro de Memoria Histórica o documentos producidos por organizaciones locales) a las artes visuales. ¿De qué manera aporta tu obra a esta "lucha por la representación"? ¿En qué medida tu obra retoma las voces de las víctimas y cómo las transforma?

ED: Una cosa es pensar en esa lucha por la representación, pero yo siempre trato de volver a un paso anterior, es decir, a ver que la lucha no es por representar sino que la lucha debería ser, y es en realidad, por lo menos desde mi trabajo, por reivindicar los horrores que pasaron. Es decir, no es por "representarlos" sino que es por la realidad de lo que pasó. Creo que a veces desde ciertos discursos académicos y desde cierto espacio de pensamiento desdibujamos los orígenes, el corazón y la base. O sea, pensar que la lucha es por la representación para mí sería como pensar que el trabajo es en vano porque no considero que sea la pregunta fundamental. La pregunta fundamental, y lo que está para que lo pensemos, no es si es válida una manera de representar, o si es más válida otra o si alguna representación está "mal hecha". Yo pienso que lo que debemos pensar y devolvernos para cuestionarnos una y otra vez es el horror de lo que pasó, y como sociedad cómo podemos tender un puente, cómo podemos hacer una malla, cómo podemos salir de ese horror y no perdernos en las discusiones de quién se acercó más a una representación válida o no. Sí, yo pensaría que para mí lo más importante es tal vez pensar qué pasaría si lo que se analiza, digamos, si lo que se piensa en espacios académicos, si la energía que se gasta en el pensamiento se enfocara más en mirar la sumatoria de las diferentes representaciones que hay y pensar qué nos están diciendo. Es decir, ¿el llamado cuál es? ¿El llamado es a decir que el trabajo de alguien en particular es el que representa de una manera más válida o mejor algo? ¿Qué tal si lo que se piensa es qué pasa si miramos juntos el trabajo de tal artista con el de tal artista, analizando la forma y la metodología de trabajo de cada uno, cada una muy válida, única y que es la que le funciona a cada uno? Porque hay que entender que no hay una manera correcta o la "mejor manera de...". Por ejemplo, hay artistas que trabajan a partir de las noticias, o a partir de los recortes de prensa, y a partir de ese análisis se genera un enunciado, uno.

La forma como yo trabajo tiene que ver con trabajar directamente con las víctimas, trabajar en comunidad. En el caso de Relicarios, por ejemplo, los objetos que los dolientes entregaron para representar cada uno a su ser querido son completamente decisión del doliente. Yo ahí no tengo absolutamente ninguna injerencia. En muchos casos, por ejemplo, hubo una reunión familiar para que la familia escogiera 
qué quería contar, cómo lo quería contar, qué era importante para esa familia. Voy a explicarlo así: hay, por ejemplo, un relicario en el cual cada uno de los hijos llevó uno de los objetos que había guardado de su papá, y el relicario suma las memorias de esos hijos para hacer el retrato del papá. Entonces ahí hay un ejercicio en el que son ellos los que deciden. Yo escucho la historia y, digamos, tomando fragmentos, pedazos de esa historia, así mismo pongo a dialogar los objetos entre sí dentro del relicario. Hay objetos, por ejemplo, que no se ven, que están puestos así porque en el trabajo de apoyo psicosocial la familia decía "esto yo quisiera que no se vea pero lo quiero dejar acá". Porque también el ejercicio emocional es soltar, el ejercicio emocional es depositar en algún lugar, y entonces no todo tiene que ser visible. Esa es la forma como yo trabajo, que es otra forma, no es "la" forma, la única forma, y por eso, para contestar tu pregunta, para mí lo importante es devolvernos siempre a lo más profundo, ir más abajo. Así la pregunta no es quién representa "bien”, es decir, la lucha no debería ser ahí. Es que un país como Colombia no merece, y yo siento que no le cabe, una violencia más dentro de los espacios que se pueden plantear de otra manera que no es la violencia.

\section{MMA: ¿Entonces lo que tú dices es que la pregunta por la representación es de segundo orden, no es la pregunta más profunda que se le puede hacer al arte?}

ED: Es que yo creo que no debería ser una pregunta. Yo pienso que para nosotros como colombianos, y lo digo porque ese es el contexto inmediato pero si sumamos el contexto es la humanidad, la pregunta no debería ser por la representación. Es que si lo que estamos haciendo es denunciar, y lo que estamos mostrando, lo que estamos trabajando, tiene como fin visibilizar, mostrar, nuestra tarea es muy chiquita dentro de la cadena de cosas que hay que hacer por la humanidad. Nuestra tarea es un punto que consiste en visibilizar lo que pasó: cómo pasó, cuáles son los orígenes de lo que pasó, cómo lo cambiamos. Es decir, nosotros somos simplemente un punto que se debe sumar a muchas otras preguntas. Es muy triste que a lo que le estemos apuntando es a ver quién representa mejor. Y ya que estamos hablando sobre estos temas de la representación, pues si ya nos metimos sigamos por ahí, si de lo que estamos hablando es de horrores que son irrepresentables, pienso entonces en Didi Huberman: los horrores son irrepresentables, impensables, inimaginables, pero pasaron. $\mathrm{Si}$ vamos a ese punto, la tarea que estamos haciendo es tratar de darle alguna forma a lo que pasó. Entonces pelearnos por quién lo representa bien o no, me parece que no es lo mejor.

\footnotetext{
MMA: Me gusta la respuesta porque cuestiona los presupuestos de las mismas preguntas que te estoy haciendo y que hacen parte de la reflexión que propone este número de la revista. Continuando en esa dirección, jcrees que en tu obra, en alguna en particular o en general, hay alguna
}

relación con la verdad? Dicho de otra manera, ¿piensas que en tu obra se hace visible una verdad que no había sido presentada antes?

ED: Yo pienso que hablar de "verdad", sobre todo en este momento político del país, se puede utilizar dependiendo de quién te lea, se puede leer de muchas formas. Yo te voy a contestar pensando en la verdad que no está ligada ni amarrada al proceso actual de Colombia donde hay una Comisión de la Verdad, el cual tiene que ver con lo político, y esa es una palabra que a mí me gusta manejar con claridad, pues tiene que ver con procesos de verdad, justicia y reparación. Yo pienso que mi trabajo contiene, en todas y cada una de las piezas que he hecho, desde Silencios hasta lo que sigue, una "verdad verdadera" que es innegable e irrefutable. Y es que cuando hablas del duelo, porque mi trabajo está planteado desde el duelo, desde el doliente, no hay manera de refutarle a una mamá, o a una esposa, o a un amigo, que su ser querido que está siendo representado a través de lo que, digamos en el caso de Relicarios, ella o él está poniendo, no hay manera de refutar que esa persona sí murió, sí está desaparecida. Cuando trabajas con testimonios directos de sobrevivientes, por ejemplo, como el General Mendieta que da un testimonio de sus trece años de secuestro, a él no le podemos quitar ni una hora de su secuestro porque la "verdad verdadera" de cuánto tiempo duró él secuestrado la sabe él. Cuando trabajas con una mujer víctima de violencia sexual, sobreviviente de una violencia sexual, como en el caso de un relicario, no hay manera de refutarle a ella la "verdad verdadera" de cuántos hombres la violaron, qué le hicieron, cómo le hicieron, qué tanto le dolió, qué tanto sufrimiento y devastación le provocaron. No hay manera de refutar eso cuando el testimonio lo está dando la persona que sabe qué le pasó. Por eso yo pienso que mi obra, a través de cada uno de los testimonios, da una "verdad verdadera". Quién es, digamos ya en el caso político en el que se está manejando el tema de la verdad, quién es culpable o no, quién es el victimario... eso ya es de otro orden, eso le pertenece a otras instancias. Hay testimonios, digamos, de Relicarios, donde me han dicho "a mi hijo lo mató tal persona". Es decir, la gente lo sabe. Si la justicia nombra al culpable o no, si lo ajustician o no, eso es de otro orden. Esa es otra verdad: es la verdad legal, que como bien sabemos, se puede dar de acuerdo con un marco jurídico, y allí puede pasar cualquier cosa. Pero la verdad irrefutable de cada uno de los testimonios está allí. La verdad del duelo está allí.

\section{MMA: ¿La verdad de una experiencia?}

ED: Sí, porque también tenemos que pensar que el duelo existe por uno mismo. Cuando, por ejemplo, los dolientes vienen y hablan de su hijo desaparecido, son muchas las violencias ejercidas: ahí pasa el desplazamiento, pasa normalmente que detrás de un testimonio hay muchos tipos 
de violencia. En la obra se está mostrando uno, pero es irrefutable.

MMA: Voy a saltar a la siguiente pregunta: ¿En qué medida participan las víctimas directamente en la elaboración de las obras?

ED: Bueno. Yo sé que esa es otra gran discusión en el campo del arte, el tema de las obras participativas, de la obra colaborativa. Eso, a nivel académico. La obra, incluso desde Río abajo, tiene un alto nivel de participación, sin que sea eso que en la academia se llama "arte participativo". Lo es, pero no dentro de las formas teóricas de lo que se suele nombrar así. El doliente tiene una participación activa en la obra, el doliente decide. Por ejemplo, en el caso de Sudarios, que es una obra donde las mujeres que se paran a dar testimonio frente a la cámara y hay un rostro contando la historia, yo no les estoy "robando" una imagen, yo no estoy lejos, no estoy escondida, no es una imagen lograda sin que las dos sepamos lo que estamos haciendo. Entonces ahí hay, digamos, no sé si quiera llamarlo "participación", por motivos teóricos, pero sí hay un acuerdo mutuo. Ellas saben lo que yo estoy haciendo, las personas son conscientes de qué es la obra, de para dónde va, del nivel de exposición, del cuidado que se tiene con su testimonio. En esa obra yo no grabo los testimonios, por ejemplo, no hay video, no hay audio. Las personas saben qué va a salir en público. Hay un mutuo acuerdo, una relación de iguales, en la medida en que ellos saben lo que me van a entregar, yo sé lo que voy a recibir y los dos estamos de acuerdo en lo que se va a ver.

MMA: Según la psicología y la psiquiatría, el trauma ocurre cuando un evento inesperado o violento produce en la persona o personas una crisis de sentido. Así lo dice, por ejemplo, Sigmund Freud cuando señala que los eventos traumáticos de una guerra que no logran ser asimilados por la persona, continúan manifestándose involuntariamente en su memoria sin que la persona pueda superarlos. Apoyándose en Freud, Walter Benjamin propone que el trauma tiene que ver con la imposibilidad de narrar o, diríamos quizás, con la imposibilidad de crear sentido. ¿De qué manera contribuye el arte, y tu obra en particular, a una re-significación, a la posibilidad de hallar un sentido? ¿Consideras que esta es una función del arte que trata temas como el tuyo?

ED: Yo empecé a trabajar con los temas de la violencia del conflicto más o menos desde el año 2004. Entonces empecé yo a recibir esos primeros testimonios. Lo primero, si lo pensamos desde el contexto de Colombia, es que a través de este tipo de trabajos se da la oportunidad de nombrar en voz alta lo que pasó. Entonces, en espacios donde en ciertas épocas ni siquiera se podía nombrar en voz alta, se generaba un espacio seguro, un espacio que no implicaba peligro físico en lugares donde aún había amenazas. Es decir, hay testimonios en Río abajo que en su momento todavía no habían sido denunciados a la Fiscalía, por temor, porque no se había llegado a ese nivel, a ese punto... bueno, no sé, por muchas circunstancias. Entonces, generar un espacio donde se pueda decir "mire, es que a mí me pasó esto" creo que es importantísimo, porque se genera un entorno para reconocer lo que pasó. Segundo, insisto, era un espacio seguro donde se podía permitir algo que en el espacio jurídico y social todavía no se podía. Es distinto el marco, digamos, de una historia un poco más reciente, donde las organizaciones de víctimas existen y donde todo esto ya era visible, aceptado, donde ya la comunidad se había organizado y todos como país decíamos "ha pasado esto".

En todo caso dentro del proceso se genera una puesta en común, porque también es importante entender que, cuando tú eres la víctima, saber que lo que te pasó no es un hecho aislado de un contexto social. No te pasó a ti "porque Dios lo quiso así", no te pasó a ti porque te cayó una maldición de repente sino que, como me pasó a mí te pasó a ti y somos tantos. El dolor, ya dejando el asunto de la justica aparte, se vuelve compartido. Sientes que hay empatía, sientes que hay una manera en la que yo puedo entender tu dolor, puedo entender lo que te pasó a partir de mi dolor, y es ahí donde se pueden establecer lazos y tejidos sociales para trabajar. Si nos ponemos realmente altruistas, a lo que le debemos apuntar es a que, si yo me conduelo con tu dolor, no vamos a dejar que este horror se repita al infinito. El tema de recordar para no olvidar puede tener sentido si yo sé lo que duele, si yo sufrí lo que he sufrido, y si tú me cuentas que a ti te ha pasado lo mismo. ¿Por qué vamos a dejar que le pase a un tercero? Entonces es ahí donde los lazos comunitarios se estrechan. Es ahí donde tal vez el arte sirve como un espacio para enunciar eso. Pero hay que entender que es una herramienta entre las muchas que hay que usar, es a una escala muy pequeña. El artista solo que va a salvar al mundo...eso no existe.

\section{MMA: ¿Qué entiendes por duelo? Sé que ya de alguna manera lo has explicado pero me gustaría precisar.}

ED: El duelo desde el psicoanálisis, de acuerdo con Freud, es un proceso de sustitución de una pérdida. Tienes una pérdida y se genera un proceso mediante el cual sustituyes el espacio que ocupaba este objeto o persona. Se genera un proceso para sustituir esa pérdida. A mí me gusta más otra teoría que no tiene que ver exactamente con "sustituir" porque no hay manera de sustituir y porque no es un proceso. Hay un teórico que a mí me gusta mucho, que se llama Jean Allouch. Él tiene un libro que se llama Erótica del duelo en tiempos de la muerte seca. Allí se plantea que el duelo no es un proceso, y que pensar el duelo como un proceso puede ser doblemente victimizante. Cuando él habla de "tiempos de la muerte seca" señala que las causas de muerte y el ritmo de muerte... que no tenemos un orden natural. Estamos en tiempos de caos, estamos en tiempos de horror, estamos en tiempos donde la 
muerte no es un proceso de la vida sino que es como una sorpresa y un accidente y vas a ser arrebatado, pero además no de cualquier manera. Y sí se muere de una manera peor hoy en día, porque es diferente morirte por una enfermedad o de viejo, pero otra cosa es un acto de desaparición forzada, o que te piquen al hijo en pedazos, que no encuentres el cuerpo completo. Esto te lo digo de testimonios que he escuchado: "ojalá que al niño tan solo lo hubieran matado". Esa es una frase que yo he escuchado o también: "¿por qué lo tenían que torturar? Ojalá tan solo lo hubiera matado". Con esas frases ya deberíamos cuestionarnos todos como país. Entonces, Allouch dice que el duelo es un nuevo estado, y que debemos entender que no es un proceso con etapas, lo cual puede culpabilizar más.

Hablábamos hace un rato del cepillo de dientes [de una mujer que no quiere botar el cepillo de dientes del hijo desaparecido]. ¿Es tarea de esa señora botar ese cepillo y superarlo rapidito? ¿Uno, lo aceptas, dos, tres..., cinco, lo superas? No, porque esa muerte no es natural. Es decir, no es tarea de ella, si no tiene un cuerpo, si a través de la ley no le han dicho que el hijo ha muerto a tal hora. Por eso hay que generar unos procesos diferentes, y porque, como el mundo es diferente, hay que generar conceptualmente un tránsito distinto. Lo que Allouch plantea es que el muerto se va llevándose consigo un trozo de sí. Un trozo de sí no es un trozo de mí: el muerto no se va llevándose un pedazo mío, sino se va llevándose lo que éramos él y yo juntos. Entonces soy yo sin mi hijo, soy yo sin mi hermano. Ese niño desaparecido, que la mamá sabe internamente que mataron, aunque en la justicia no hay nadie que le haya dicho... no hay un cuerpo, ella no enterró. Porque por eso importa el tema de los rituales de la muerte. Es decir, la humanidad siempre se ha preocupado por eso. Como aquí estamos interrumpiendo esos órdenes, estamos interrumpiendo todo esto, ella queda sin cómo pasar a esa famosa lista de etapas del proceso de duelo, y tampoco es justo hacerla pasar por esa lista. Se trata de aprender a pensar que somos contenedores de vacío. Vamos perdiendo. Somos completos y vamos perdiendo, para siempre.

\section{MMA: Qué bello y qué fuerte. Pasando a otro tema, según Doris Salcedo los artistas siempre están "en el filo de la navaja, en un punto muy delicado, en cuanto a qué se dice, a qué se calla.” ¿Cómo se manifiesta en tu obra esta tensión entre lo que se dice y lo que se calla, entre la voz y el silen- cio, entre lo que se ve y lo que no se ve?}

ED: Bueno, para mí desde mi práctica, desde mi proceso, lo más importante, el límite, la línea, se traza en el momento en el que yo puedo llegar a poner en peligro al otro. Para mí esa línea es absolutamente clara. En qué momento pongo en peligro de cara a denunciar, de cara a tratar de sacar una obra más importante. Porque cuando yo empecé a trabajar en regiones, cuando yo empecé a trabajar en ciertas zonas, empiezas a entender lo que son las fronteras invisibles. Es decir, se llama "frontera invisible", no es que la vayas a ver, es que la tienes que sentir. Hay un punto también entre cuál es el contexto de "allá" y como se traduce al contexto de "acá". Cómo, digamos, con el trabajo con víctimas, por ejemplo, muchas veces pasa que tú les dices que una obra va a salir en una revista. Debes tener conciencia sobre quién va a ver, en qué momento con ese testimonio, con esa obra, tú puedes poner en peligro a esa persona, en un contexto donde los marcos del peligro no son tan claros tampoco. Entonces para mí, lo que callo, y callo mucho, tiene que ver directamente con la protección de la vida porque me parece que la línea es cuidar la vida. Y es el respeto también, para mí la línea está en el respeto, está en el honrar. Sobre todo porque yo estoy trabajando una obra que si bien denuncia la violencia, que, digamos, está inscrita dentro de ese marco de lo que llamamos "Conflicto" y de lo que seguirá, aunque para mí el tema del cambio de marco político no afecta, en la medida en la que yo estoy trabajando el duelo y en esa "verdad verdadera". Independientemente de que nombremos quién es el victimario, que hoy en día puede ser el uno o puede ser el otro, o que haya otros victimarios, la verdad para mí sigue siendo la misma. Lo que muestro, como siempre he trabajado desde el doliente, tiene que ser y tiene que obedecer al amor, tiene que obedecer al respeto, tiene que obedecer a la dignificación, hacia la manera con que me están entregando a mí el testimonio.

En Río abajo, por ejemplo, las prendas no las encontré en el río, sino que me las entregaron los dolientes: es la prenda que en la familia estaba guardada por si el desaparecido volvía. Ahí está. Hay una camisa, por ejemplo, que la mamá nunca había lavado porque "fue la última que usó el niño la última vez que lo vi". O una camisa con la que la mamá dormía abrazada. Entonces lo que yo muestro tiene que obedecer a ese nivel de cuidado, a ese nivel de amor. Yo estoy pensando si el "espectador principal", si cabe aquí el uso del término, si el espectador principal de la obra son estos dolientes. Lo que yo quiero es que cuando esta mujer, la mamá que dormía con la camisa abrazada, vaya a la exposición, se encuentre algo a lo que ella le pueda sostener la mirada de frente. O sea, que ella sienta que con el mismo amor y respeto que ella me entregó el objeto, así a través del arte, la historia queda contada. Para mí lo más importante es ese círculo. Desde ahí, lo que decido mostrar siempre está de cara a cómo yo lo recibí. Te hablaba ahora del relicario en el que el objeto me llegó en una bolsita de regalo. Yo no voy a primar nunca el discurso de la violencia ni el discurso político, porque yo estoy trabajando en la esfera del duelo, ni voy a primar quién es el victimario. Es decir, yo sé quién es el victimario pero esta no es una obra para contar eso. Los dolientes saben quién es el victimario pero el gesto de despojarse de los objetos, de participar en la obra, de buscar y escribirme mensajes porque quieren participar en la obra, de personas que son espectadores que han ido a ver la obra y me mandan un mensaje como por ejemplo: "yo quiero que mi hermano esté en alguno de los espacios que usted está haciendo". Cuando se genera eso, lo que muestro tiene que obedecer a su sentimiento. Nunca obedecerá a 
primar la denuncia, porque no estoy trabajando desde ahí. No estoy diciendo que sea válido o no: es una obra que se ocupa de una cosa distinta. Entonces, de ahí lo que muestro y lo que callo siempre tiene que ver con el respeto a la vida y al honor, y a la honra, de los dolientes.

MMA: Es muy emocionante lo que dices. Me has dicho unas cosas muy hermosas y muy profundas hoy.
ED: Gracias, me generas la confianza para decirlo así también. Yo entiendo que desde un discurso académico muchas veces de entrada esto está invisibilizado, porque no es lo que interesa oír. Pero yo pienso que el arte, si no es una herramienta para servir a los demás, es un camino destructivo y que no va a ningún lado. Finalmente es en ese sentido que el arte puede ser transformador y sanador, no en el sentido de que "como ya contamos esto con el arte, quedó listo". No, es desde la humanidad.

\section{Imágenes}
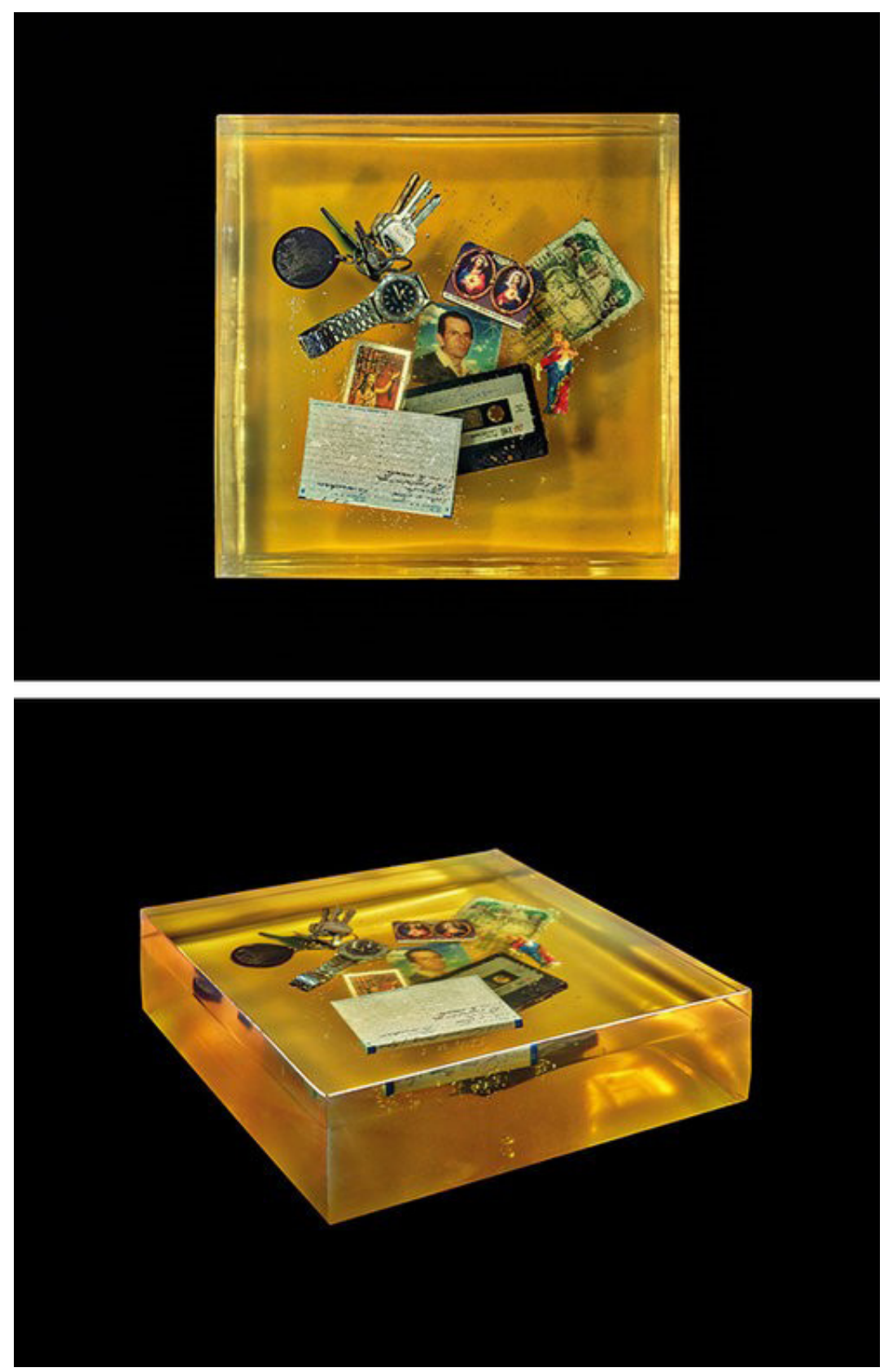

Fuente: https://www.erikadiettes.com/relicarios-ind Imøgenes reproducidas con permiso de la artista 


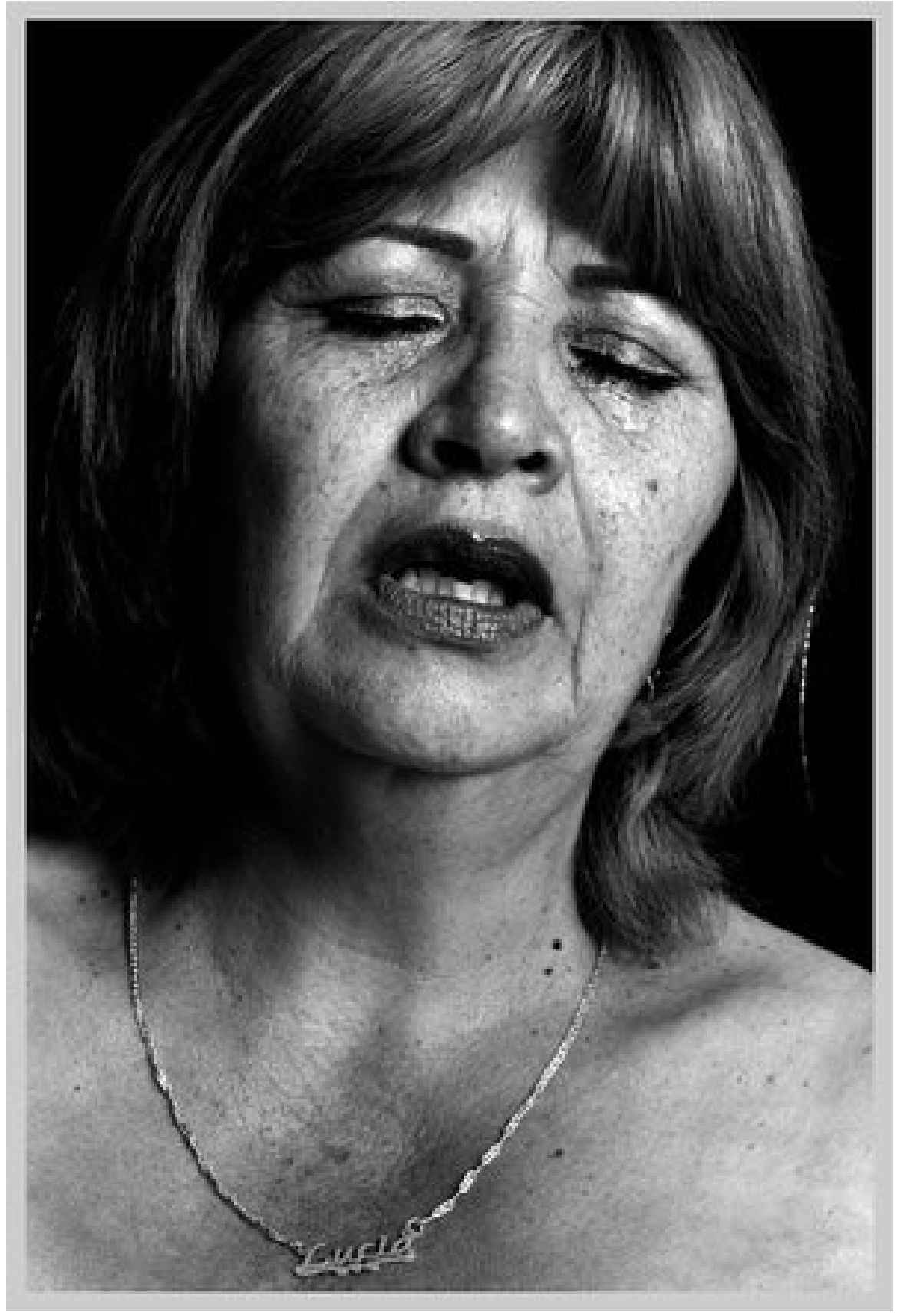

Fuente: https://www.erikadiettes.com/sudariosobra Imagen reproducida con e permiso de la artista 


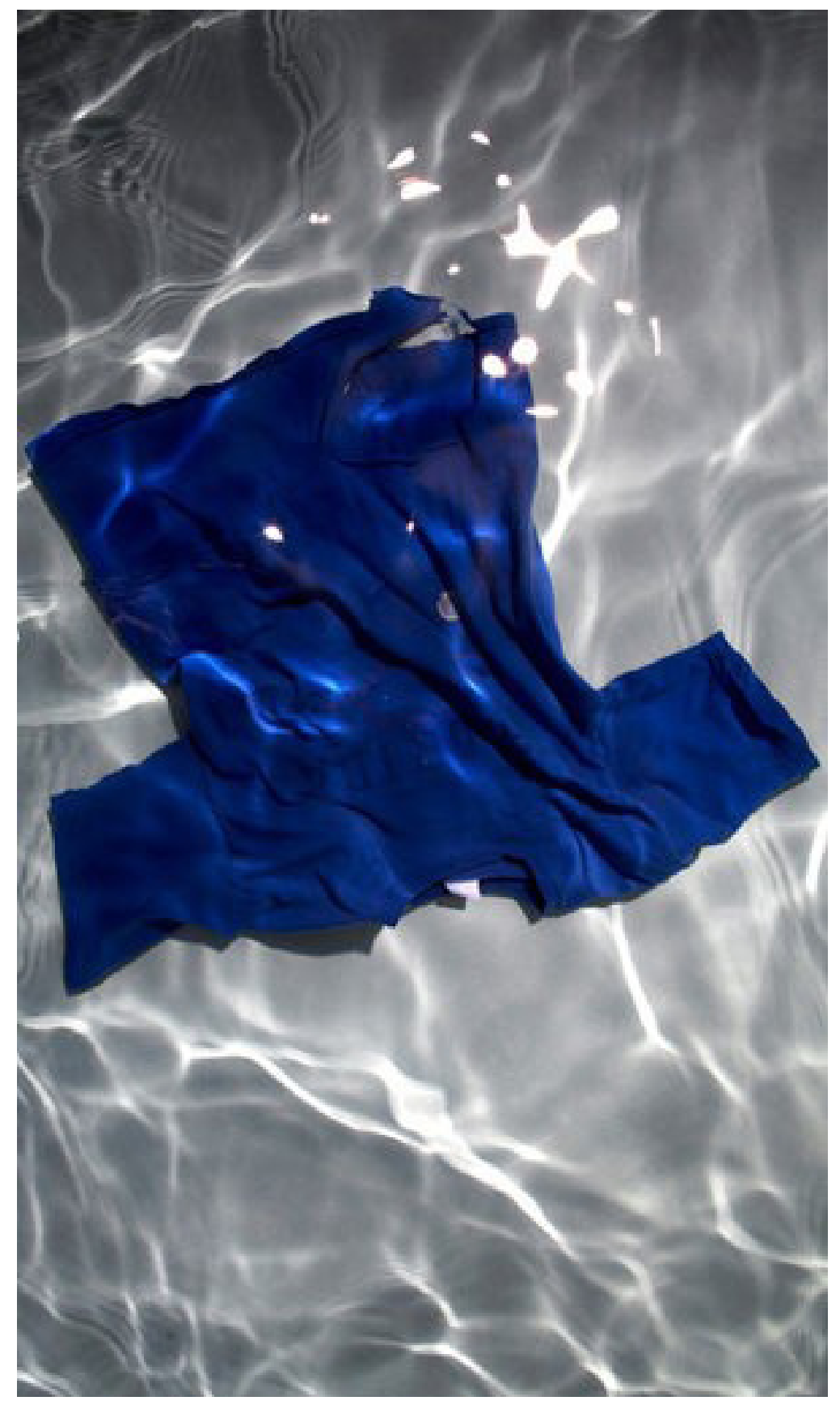

Fuente: https://www.erikadiettes.com/rioabajoobra Imagen reproducida con el permiso de la artista 